\title{
Traumatic Stress Disorder Observed in an Adult Wild Captive Wolf (Canis lupus)
}

\author{
Jay S. Mallonée \\ Wolf and Wildlife Studies \\ Libby, Montana \\ Paul Joslin \\ The Alaska Wildlife Alliance \\ Anchorage, Alaska
}

\begin{abstract}
Tenino was an adult female wolf, born in the wild and placed into captivity at 1 year of age because of her participation in livestock depredation. Her method of capture, well documented, involved being darted twice by helicopter and translocated twice. This method of capture would have exposed her to the 2 factors that are important in the etiology of posttraumatic stress disorder in humans: uncontrollability and unpredictability. In a case study we conducted, Tenino displayed symptoms that were similar to those of humans with posttraumatic stress disorder. These symptoms included hypervigilance, exaggerated startles, generalized fear, avoidance, and arousal. She also displayed looking up behaviors that occured during the presence of perceived threats such as a neighboring rancher's gunshots; the keeper truck; some keeper activity; and, occasionally, aircraft. When compared to 3 other wolves, including her enclosure mate, these behaviors were exclusive to Tenino.
\end{abstract}

Animals other than humans, subjected to various experimental psychological trauma, often produce behavioral disturbances that resemble human posttraumatic stress disorder (PTSD) symptoms (Kolb, 1987; van der Kolk, 1987; van der Kolk, Greenberg, Boyd, \& Krystal, 1985). This suggests that common etiological factors may be involved in the development of PTSD in ani-

Requests for reprints should be sent to Jay S. Mallonée, Wolf and Wildlife Studies, 211 Silver Butte, Libby, MT 59923. E-mail: wolffinder@kvis.net 
mals and humans (Foa, Zinbarg, \& Rothbaum, 1992) and that animals, like humans, can suffer from emotional trauma.

\section{DESCRIPTIONS}

PTSD is an anxiety disorder that develops in response to a psychologically traumatic event outside the range of normal experience (American Psychiatric Association, 1987). Most studies have found that the likelihood of developing PTSD is directly proportional to the severity of the stressor, such as bodily injury (Foy, Resnick, Sipprelle, \& Carroll, 1987; Helzer, Robins, \& McEvoy, 1987; Speed, Engdahl, Schwartz, \& Eberly, 1989) and how the victim perceives the threat (Kilpatrick et al., 1989). Although injury and perception of danger can increase the prevalence of PTSD, exposure to life-threatening circumstances is not always sufficient to cause this disorder (Rachman, 1989; Saigh, 1988).

As defined by the American Psychiatric Association (1987), human PTSD victims exhibit a combination of symptoms from three categories of behavioral disturbances: re-experiencing (nightmares, flashbacks, intrusive recollections), avoidance (avoid thoughts, feelings, or activities; decreased interest in activities), and arousal (sleep problems, hypervigilance, exaggerated startles, problems concentrating). Some of these disturbances resemble features of other emotional disorders, but the entire syndrome, as just described, is found only in PTSD sufferers (Foa et al., 1992).

Obviously, the study of PTSD in animals is limited to nonverbal observations, and their subjective experiences of some symptoms such as flashbacks, nightmares, and intrusive recollections cannot be measured. Despite these limitations, the behavioral disturbances in animals following psychological trauma often match the most prominent and cardinal features of PTSD in humans (Mineka, 1985).

\section{Exposure to Stressors}

Common throughout the traumatic events experienced by animals used in experiments or human PTSD sufferers is exposure to stressors that the victim cannot control, stressors that are unpredictable, or both (Masserman, 1971; Mineka \& Kihlstrom, 1978). Both human PTSD victims and animals used in experiments who have experienced uncontrollable, unpredictable shock show heightened generalized fear and arousal expressed as difficulty sleeping, elevated heart rate and blood pressure, hypervigilance, and exaggerated startles. Uncontrollability and unpredictability also produce some of the avoidance behaviors observed in humans with PTSD and animals who display PTSD symptoms (Maier \& Keith, 1987; Moye, Hyson, Grau, \& Maier, 1983). 


\section{About Tenino}

Tenino, a 2-year-old female timber wolf (Canis lupus) when the study began, was one of six pups born (April 1990) in the first litter of the Ninemile pack in Ninemile Valley, Montana. The litter was orphaned at 6 months of age after the alpha female apparently was shot and a vehicle killed the alpha male as he attempted to cross nearby Interstate 90. U.S. Fish and Wildlife Service (USFWS) biologists and local ranchers (who owned the land where the pack resided) fed the pups roadkill deer in an attempt to increase their chances of survival. Human interference (scent, presence) was kept to a minimum and apparently did not impact grossly the pups' behavior (J. Fontaine, personal communication, July 1993). The pups eventually began killing deer and other prey on their own.

Sometime prior to the Spring of 1991, one of the pups apparently died of natural causes and another kept a distance from the pack. In the Spring of 1991, the remaining four pups apparently killed two yearling steers in the Flathead Indian Reservation. USFWS biologists attempted to capture the pups by darting them from a helicopter. Although a male pup escaped, the other three were captured and placed in a temporary kennel for several days. The three wolves were fitted with radio collars and then transported to Glacier-Waterton National Park, Montana, where they were released (April 1991). The pups, now yearlings, stayed together approximately 1 week; then the pack disbanded.

Tenino traveled across the Continental Divide into eastern Montana. Near the town of Dupuyer, approximately $60 \mathrm{~km}$ from Glacier-Waterton National Park, she killed two lambs. For the second time, USFWS biologists darted Tenino by helicopter and placed her in another kennel temporarily. Because she was considered young enough to possibly adapt to captivity, the USFWS contacted Wolf Haven International, in Tenino, Washington, to place Tenino into captivity rather than euthanizing her (J. Fontaine, personal communication, March 1994). Tenino arrived at Wolf Haven International on June 18, 1991, where, 3 weeks later, she was joined by her enclosure mate, Joe. Two other timber wolves in the wild have been captured in a similar manner as that of Tenino and placed into captivity (S. Fritts, personal communication, January 1994). Extensive behavioral studies on these animals, however, have not been conducted.

\section{Effects of Capture}

Capture of an animal in the wild can cause the animal extreme psychological stress (Hediger, 1950), which often is more detrimental than physical trauma (E. Klinghammer, personal communication, May 1995). These animals live in their own specific world and respond to the environment based on their physiology, perceptual abilities, and past experience. This is referred to as the animal's Umwelt and was explained in depth by von Uexküll (1937). 
Capturing animals in the wild disrupts or destroys their previous Umwelt, and the animals must construct a new, subjective world based on their captive conditions. This would require the animals to struggle with completely new and strange factors by fitting them into a new perception of a captive world. It would be expected that not every newly captured individual could complete such a task successfully. In addition, success would be contingent not only on the animal's adaptability but also on the animal's access to the tools-proper housing, adequate space, food, low stress—-needed for building a new, subjective world.

Woolpy and Ginsburg (1967) successfully habituated captive wild wolves to humans, involving animals who ranged in age from pups to adults. On a daily basis, each wolf was moved from the living area for a period of time and confined with a human observer inside a kennel. Over a period of several months, the wolves' reactions to the observer ranged from extreme fear to acceptance. Their wolves, however, were not exposed to the trauma experienced by Tenino, nor was her housing situation conducive for applying the procedures outlined by Woolpy and Ginsburg. Habituating Tenino to humans in this manner, therefore, was not attempted.

Tenino exhibited symptoms similar to those of humans with PTSD. We propose that not only did the traumatic nature of Tenino's capture contribute to her symptoms of PTSD, but that stressors in captivity perpetuated her PTSD symptoms and interfered with her ability to adapt adequately to her captive situation.

\section{METHOD}

\section{Subjects}

As noted earlier, Tenino, born in 1990, spent her first year of life in the wild. For comparison with Tenino's behaviors, three additional wolves were used as behavioral controls. All three wolves were raised in captivity. Joe was born in 1987 and was Tenino's enclosure mate. He came to Wolf Haven from Hamilton, Montana, having spent his first 4 years at a hybrid breeding facility. At this facility, he lived alone in an enclosure approximately 67 square meters in size next to several domestic dogs and, apparently, two other timber wolves (Canis lupus). Gris Gris and Gyrene were siblings and were born at Wolf Haven in 1984. They were born in a litter of four, with the other two wolves also residing at Wolf Haven. In 1992, Gris Gris began developing cataracts in both eyes. In 1993, she and Gyrene were removed from the public tour and placed in the enclosure next to Joe and Tenino. Although Gris Gris's eyes appeared cloudy, Gyrene's did not. Their keepers reported, however, that vision in both animals was obscured. Neither animal had undergone a medical eye examination, so to what extent their vision was impaired remains unknown. Even after hundreds of hours observing Gris Gris or Gyrene, the first author never observed them 
trip, bump, or become impeded by trees or bushes within their enclosure or the enclosure fence.

\section{Design and Procedure}

Behavioral observations of Tenino and the control animals began in May 1992 and concluded in January 1995. Although observation time totaled $327 \mathrm{hr}$, the data used to demonstrate possible PTSD in the study animal represented $51 \mathrm{hr}$ of observation. These $51 \mathrm{hr}$ represented the context in which all four study animals could be observed simultaneously with each having the opportunity of responding (or not responding) to the same event or stimulus-children screaming or running nearby, the food truck approaching the enclosures, aircraft flying overhead, and gunshots. This context allowed Tenino to be compared with the other three wolves for the same event and helped to demonstrate how her behavior was so different from that of the other wolves. When only one or two wolves could be seen at any one time and their reactions to events could be recorded comprised the remaining study hours. These data helped support what we saw when all four wolves were observed together and simultaneously. Thus, we believe that the $51 \mathrm{hr}$ of observation represented here are sufficient to demonstrate the differences between wolves in the wild placed into captivity and those raised in captivity.

Observations were made during daylight hours (early morning until dusk) and as time permitted. We originally wanted to observe the wolves throughout a 24-hr period to gain an accurate view of their activity periods. Wolf Haven denied this request. We were allowed to make observations only during the day; at night, the wolves were off limits. During an observation session, data were collected in 1-min intervals using a coded system that allowed the observer to take notes rapidly. Such a method allowed data to be gathered not only on the individual behavior of animals but also on their interactions (Mallonée, 1991). Observation sessions typically lasted from 1 to $2 \mathrm{hr}$ and often were videotaped for documentation of particular behaviors, especially those that were specific to Tenino. Periodically, however, weather conditions, keeper activity, and politics limited our availability to animals in the study, so often we took what we could get in terms of time spent with the wolves.

Two observation areas were used: (a) at a platform $5 \mathrm{~m}$ from the enclosure fence where the observer sat near ground level, and (b) at the fence directly in front of the platform where the observer sat on the ground (Figure 1). From the beginning of the study, all observations were made from these two areas. Several hundred hours of observation demonstrated that the wolves' behaviors did not change depending on where the observer was stationed. 


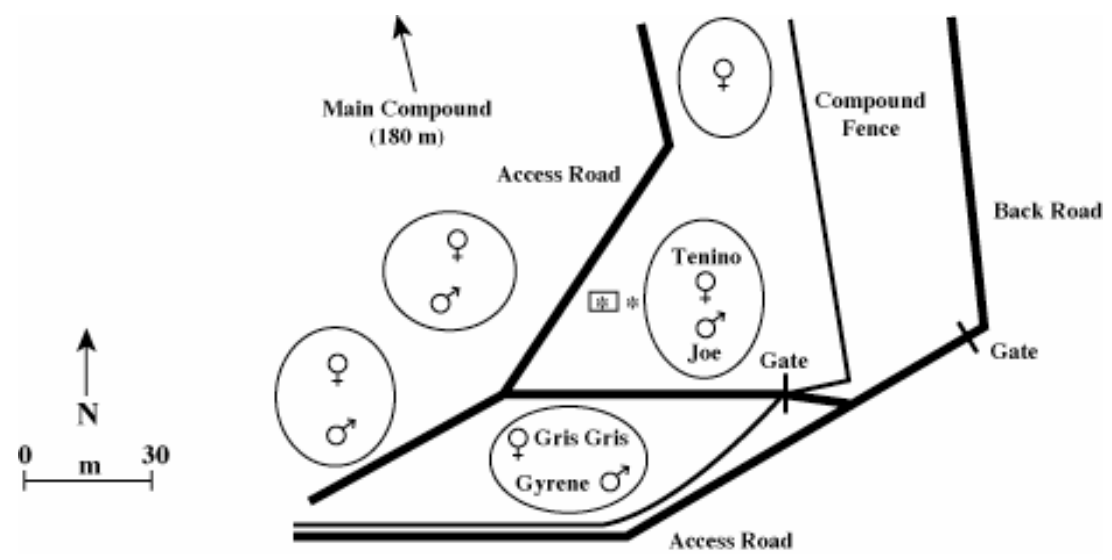

FIGURE 1 Dimensions of the study animal's enclosure and distance to surrounding wolf enclosures. *Observation areas.

In addition, a video camera occasionally was placed at the observation areas when no observer was present. Eleven hours of observation recorded in this manner demonstrated virtually no difference in Tenino and her enclosure mate's behaviors and interactions when the observer was present or absent. If behavioral changes did occur, it was when the observer arrived at the observation areas and when the observer was leaving these areas. Occasionally, for 10 to $15 \mathrm{~min}$ as the observer was either coming or going, the wolves would focus more on the observer and what he was doing rather than continue with their own behavior at that moment. The remote camera demonstrated, however, that both wolves quickly continued their routine soon after the observer sat down or left the area.

Tenino and Joe were housed in a 2,700-square-meter wooded enclosure (Figure 1). They were $12.5 \mathrm{~m}$ from the nearest enclosure that housed the two other wolves, Gyrene and Gris Gris. The observation area at the fence of Joe and Tenino's enclosure afforded views of all four wolves used in our study. On two other sides of Tenino and Joe's enclosure were other wolves housed in an enclosure $28 \mathrm{~m}$ away and a second enclosure $29 \mathrm{~m}$ away. On the last side of their enclosure was the compound fence, and beyond this an access road that eventually passed within $18 \mathrm{~m}$ of Tenino and Joe's enclosure. All the animals in this area were limited to human presence due to their particular needs. Only the keepers, the study observer, an occasional board member, and photographer had access to this area.

One of the goals of our study was finding methods that would enhance Tenino's adjustment to captivity. In doing so, baseline data were collected to document the basic behaviors exhibited by both Joe and Tenino and their social interactions. Apparent PTSD symptoms were found to be a part of Tenino's basic behaviors and are reported here. The several measurable behaviors exhibited by Tenino were an- 
alyzed according to the context in which they occurred, which has proven to be a useful technique in elucidating the probable cause of some behaviors (Mallonée, 1991).

\section{RESULTS}

Tenino's behavioral symptoms of PTSD could be grouped naturally into three different categories: hypervigilance, exaggerated startles, and looking up behaviors. Hypervigilance was defined as excessive monitoring of the surrounding environment, often to the point of disturbing rest periods. Exaggerated startles referred to overreactions to a stimulus ranging from the snap of a twig or gunshots to no apparent reason. Looking up behaviors occurred under many different contexts but could be grouped into two categories: look-ups involving aircraft and those involving apparently stressful circumstances.

\section{Hypervigilance}

Hypervigilance among the four wolves was measured during their rest periods, during which they were sitting or lying down for a period of time. Seven rest periods were observed, ranging from 11 to $51 \mathrm{~min}$ (totaling $218 \mathrm{~min}$ ), in which all four animals were monitored. A percentage of the time spent in four observed resting behaviors was obtained for each animal. The behaviors were:

1. Seated (sitting and not looking around)

2. Seated/attending (sitting but monitoring their surroundings)

3. Locomotion (active, e.g., walking or trotting to a new rest area or a brief activity period before sitting down and continuing to rest)

4. Attending (deliberately getting up and walking or trotting to an area, stand attending to an apparent disturbance, then sitting and continuing to rest)

Extensive differences were found between Tenino's rest periods and those of the other three wolves (Figure 2). Tenino spent much less time seated $(28.0 \%, 61$ min) during rest periods than did Joe (93.6\%, $204 \mathrm{~min})$, Gyrene $(98.9 \%, 215.5$ $\mathrm{min}$ ), and Gris Gris (94.9\%, $207 \mathrm{~min})$. When she was seated, Tenino spent more time attending to her surroundings $(45.9 \%, 100 \mathrm{~min})$ than $\mathrm{did}$ Joe $(3.9 \%, 8.5 \mathrm{~min})$, Gyrene (0\%, $0 \mathrm{~min}$ ), or Gris Gris (0\%, $0 \mathrm{~min})$. Finally, Tenino spent more time moving around the enclosure during rest $(21.1 \%, 46 \mathrm{~min})$ than did Joe $(2.5 \%, 5.5$ $\mathrm{min})$, Gyrene $(1.1 \%, 2.5 \mathrm{~min})$, or Gris Gris $(4.6 \%, 8 \mathrm{~min})$. In regard to attending, the observer found little difference between Tenino and the other wolves. Among the other three wolves, no real differences in resting behaviors were found. 


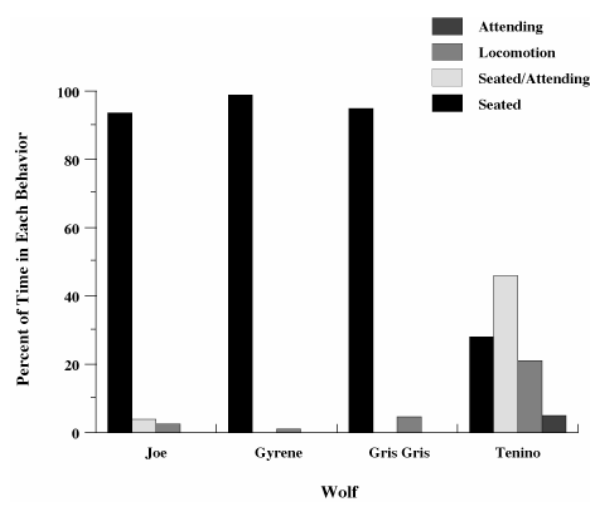

FIGURE 2 Hypervigilant behaviors observed in Tenino during rest periods.

During rest, Tenino often would lift her head to look around if she was seated with her head on the ground. She would do the same if she was lying on her side. The other three wolves rarely lifted their heads to look around when resting. Tenino spent a great deal of her rest periods attending to her surroundings, mostly as she sat, and rarely got up to attend to anything specific. In this regard, she behaved the same as the other three wolves.

\section{Exaggerated Startles}

Fourteen exaggerated startles were observed in Tenino for a variety of reasons (Table 1), most of which seemed to be related to apparently stressful situations or at least to those situations that she had the opportunity to perceive as stressful. No exaggerated startles were observed in the other three study animals.

\section{Looking Up Behaviors}

Along with exaggerated startles, looking up behaviors set Tenino apart from the other wolves. Tenino exhibited $98.3 \%(n=113)$ of 115 observed looks up, and Joe accounted for the other $1.7 \%(n=2)$. Gyrene and Gris Gris did not look up. Because all observations of the four animals were made simultaneously, each had the opportunity to look up under similar conditions. Joe's looks up occurred when two ducks flew above the enclosure and once when the keeper truck approached the enclosure.

Tenino looked up for a variety of reasons, which could be classified into two groups of apparent causes: aircraft and stress-related factors (Figure 3). Of the 122 
TABLE 1

Description and Apparent Causes of the 14 Exaggerated Startles Observed in Tenino

\begin{tabular}{|c|c|c|}
\hline Apparent Cause & $n$ & Description \\
\hline Approaching truck & 2 & $\begin{array}{l}\text { Food truck approached enclosure area but was several hundred meters away and } \\
\text { apparently out of Tenino's visual range. It stopped periodically and the } \\
\text { keepers fed the wolves. All wolves in the area were excited (trotting, } \\
\text { whining, etc.), including Tenino. She was trotting, then jumped as if startled } \\
\text { then continued pacing. No startles were observed in the other three study } \\
\text { animals. } \\
\text { The same food truck came inside the main compound and was still several } \\
\text { hundred meters away, presumably out of Tenino's visual range. Tenino was } \\
\text { standing on a knoll and attending to the compound. While doing so, she } \\
\text { jumped as if startled and looked up then continued attending to the } \\
\text { compound. }\end{array}$ \\
\hline General nervousness & 1 & $\begin{array}{l}\text { Tenino apparently tense (flat ears and excessive looking up while trotting, } \\
\text { walking, standing, and looking around). Of the other three study animals, one } \\
\text { was sitting, another was laying on its side, and the third was walking slowly } \\
\text { around. Construction was occurring approximately } 120 \mathrm{~m} \text { away, which } \\
\text { consisted of hammering noises. At one point as Tenino trotted around the } \\
\text { enclosure, she jumped as if startled, then continued pacing. }\end{array}$ \\
\hline $\begin{array}{l}\text { Gunshots from } \\
\text { neighboring } \\
\text { rancher }\end{array}$ & 2 & $\begin{array}{l}\text { Truck approached enclosure but was still } 200 \mathrm{~m} \text { away and presumably out of } \\
\text { Tenino's visual range. It stopped periodically and the keepers fed the wolves. } \\
\text { All surrounding wolves were either trotting or walking, including Tenino. } \\
\text { She also stood periodically to attend to the compound and the approaching } \\
\text { truck. Numerous gunshots had been occurring (approximately } 150 \text { to } 200 \mathrm{~m} \\
\text { away) for } 9 \text { min on the neighboring rancher's land. Tenino looked up } \\
\text { frequently since the gunshots began. One of the gunshots caused her to jump } \\
\text { as if startled, then she continued to monitor the compound. } \\
\text { Four min after the exaggerated startle described above, another gunshot caused } \\
\text { Tenino to jerk her head and body around and face the direction of the shot. } \\
\text { She then continued to attend to the approaching truck. No startles were } \\
\text { observed in the other three study animals. }\end{array}$ \\
\hline $\begin{array}{l}\text { Backfiring wood } \\
\text { chipper }\end{array}$ & 2 & $\begin{array}{l}\text { A wood chipper was functioning } 100 \mathrm{~m} \text { from enclosures of the four study } \\
\text { animals. It was on for } 49 \text { of the previous } 55 \mathrm{~min} \text { and was in a shallow out of } \\
\text { visual range. The three other study animals were sitting and Tenino stopped } \\
\text { trotting and walking and sat down. As she did, her ears went flat briefly. } \\
\text { Three min later, the chipper backfired and Tenino jumped up and stood } \\
\text { looking toward the chipper. The other wolves remained seated. She then } \\
\text { began walking with flat ears, then stopped and stood motionless as a prop } \\
\text { plane flew overhead, then with flat ears she looked up. She continued } \\
\text { walking to her sitting area and sat as the chipper stopped. }\end{array}$ \\
\hline
\end{tabular}

(continued) 
TABLE 1 (Continued)

\begin{tabular}{|c|c|c|}
\hline Apparent Cause & $n$ & Description \\
\hline & & $\begin{array}{l}\text { The wood chipper had been off and on for approximately } 2 \mathrm{hr} \text { and two } \\
\text { photographers had been taking pictures of Tenino and her enclosure mate for } \\
30 \text { min. They had previously been at a nearby enclosure ( } 28 \mathrm{~m} \text { away) for } 15 \\
\text { min. Tenino continually sat briefly with flat ears, then trotted to a vantage } \\
\text { point to monitor the photographers then returned and sat. Joe was laying on } \\
\text { his side and the other two study animals were out of view. While Tenino was } \\
\text { attending to the photographers, the chipper produced multiple backfires and } \\
\text { Tenino jumped as if startled and trotted immediately to the other side of the } \\
\text { enclosure (closest to the chipper) and stood looking toward the chipper. }\end{array}$ \\
\hline Neighboring animal & 1 & $\begin{array}{l}\text { The keeper truck was parked approximately } 17 \mathrm{~m} \text { from Tenino's enclosure and } \\
\text { the keepers were feeding nearby wolves. One of the keepers walked and } \\
\text { circled behind the enclosure of Gyrene and Gris Gris. Tenino trotted closer to } \\
\text { stand and look where he went. A nearby animal then barked and Tenino } \\
\text { jumped as if startled then continued looking for the keeper. Joe remained } \\
\text { seated and the other two study animals were walking and following the } \\
\text { keeper who was circling their enclosure. }\end{array}$ \\
\hline $\begin{array}{l}\text { A wolf drinking } \\
\text { water }\end{array}$ & 1 & $\begin{array}{l}\text { Tenino and Joe were laying on their side and Gyrene in the adjacent enclosure } \\
\text { was seated. Gris Gris was drinking water and her bucket hit the fence pole } \\
\text { and made a loud noise. Tenino bolted upright and sat looking toward the } \\
\text { sound. She then laid back down. Gyrene and Joe remained the same. }\end{array}$ \\
\hline Loud children & 2 & $\begin{array}{l}\text { A children's tour had been near the gift shop area (approximately } 200 \mathrm{~m} \text { away) } \\
\text { for at least } 37 \text { min. They were extremely noisy and occasionally screamed. } \\
\text { The study wolves were sitting or laying on their side except for Tenino. She } \\
\text { would constantly sit briefly, then trot or walk to a vantage point and attend to } \\
\text { the gift shop area. While sitting or attending, her ears were often flat and she } \\
\text { looked up periodically. The other three animals did not display any of these } \\
\text { behaviors and appeared relaxed. At one point, while standing and looking } \\
\text { around with flat ears, she jerked her head and body in the direction of the } \\
\text { children and attended to them. She did the same while sitting and clearly sat } \\
\text { attending to the children. }\end{array}$ \\
\hline Unknown & 3 & $\begin{array}{l}\text { Tenino and her enclosure mate were laying on their side as another study animal } \\
\text { walked slowly around its enclosure. The fourth wolf was out of view. Tenino } \\
\text { then bolted upright and sat looking toward the compound. No extraordinary } \\
\text { sounds or events were observed or heard by the observer. The other animals' } \\
\text { behavior remained the same. She then laid back down until } 3 \text { min later when } \\
\text { she did the same thing. } \\
\text { On another occasion, when the wood chipper was being set up nearby, Tenino } \\
\text { was walking around the enclosure then jumped as if startled. The chipper was } \\
\text { not turned on yet and no extraordinary event was seen or heard by the } \\
\text { observer near the wood chipper or elsewhere. The wolves had been fed } \\
\text { earlier and all were eating meat except for Tenino. }\end{array}$ \\
\hline
\end{tabular}




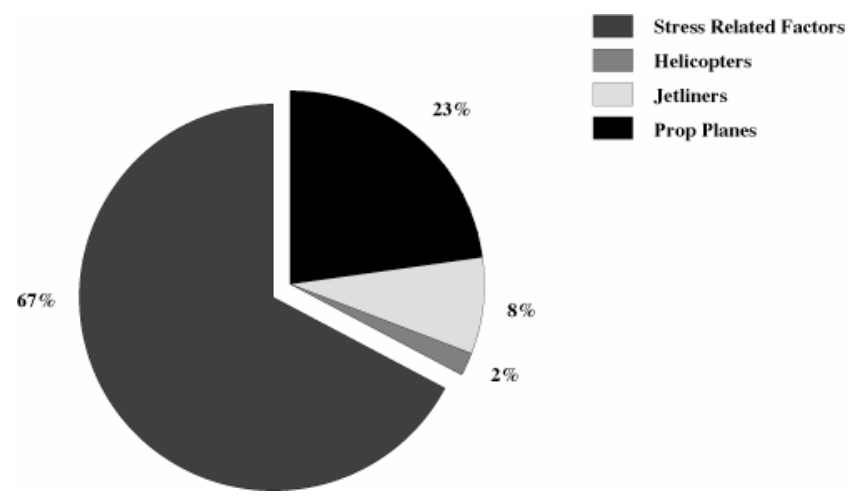

FIGURE 3 Apparent reasons why Tenino looked up. Tenino looked up a total of 113 times: 37 for aircraft and 76 for stress-related factors.

aircraft that were noted flying above Wolf Haven during observation sessions (approximately $335 \mathrm{~m}$ or higher), Tenino looked up at $30.3 \%(n=37)$ of them. She, therefore, did not look up at every plane that passed by, especially those at a greater altitude. Despite altitude differences, however, when she did look up at aircraft, she apparently attended more to prop planes $(70.3 \%, n=26)$ than jets $(24.3 \%, n=$ 9). Only three helicopters were observed flying over Tenino and Joe's enclosure, two of which involved Tenino looking up.

The majority of aircraft looks up occurred during rest periods when Tenino apparently was in a calm, but still hypervigilant, state. Her apparent responses to the planes varied greatly. She often would glance up, monitoring the passing plane as if it were not an immediate threat. Other times she would turn and look up over her shoulder and go out of her way to watch a plane. She even would watch it long enough so that her head moved with the plane, indicating that she was tracking it.

The majority of looks up displayed by Tenino did not involve aircraft. When these looks up are grouped by the context (apparent cause) in which they occurred (Table 2), it appears that most were caused by circumstances that might have been stressful to Tenino or at least perceived as threatening. During stress-related looks up, Tenino's anxiety level obviously was higher than during aircraft looks up, as evidenced by flat ears, hypervigilance, and increased generalized fear, avoidance, and arousal. She occasionally displayed these behaviors when aircraft were present, but they appeared to be commonplace during stress-related looks up.

\section{DISCUSSION}

In PTSD victims, persistent arousal and increased generalized fear usually are expressed as hypervigilance and exaggerated startles (American Psychiatric Associa- 
TABLE 2

Stress-Related Look Ups Observed in Tenino and Their Apparent Cause

\begin{tabular}{|c|c|c|c|c|c|}
\hline Apparent Cause & $n$ & $\begin{array}{c}\text { Time } \\
\text { Observed }^{\mathrm{a}}\end{array}$ & $\begin{array}{l}\text { Look Ups } \\
\text { Per Hour }\end{array}$ & $\%^{\mathrm{b}}$ & Associated Behaviors \\
\hline $\begin{array}{l}\text { Nearby construction } \\
\text { (several } 100 \mathrm{~m} \text { or } \\
\text { less) }\end{array}$ & 15 & 7.08 & 2.12 & 13 & $\begin{array}{l}\text { Attended to noise, if any, and } \\
\text { usually sat. Although } \\
\text { apparently calm, she often had } \\
\text { flat ears. }\end{array}$ \\
\hline $\begin{array}{l}\text { Distant human presence } \\
\text { (approximately } 100 \\
\text { m or more) }\end{array}$ & 15 & 4.22 & 3.55 & 13 & $\begin{array}{l}\text { Attended to sounds while sitting } \\
\text { or active, often with flat ears. }\end{array}$ \\
\hline $\begin{array}{l}\text { Close human } \\
\text { presence-mostly } \\
\text { keeper activity } \\
\text { (Approximately } 100 \\
\text { m or less) }\end{array}$ & 9 & 1.02 & 8.82 & 8 & $\begin{array}{l}\text { Kept her distance and attended to } \\
\text { the person's activities. She } \\
\text { rarely sat. Displayed extreme } \\
\text { forms of anxiety during this } \\
\text { context, such as crouching } \\
\text { with flat ears, standing } \\
\text { motionless, and exaggerated } \\
\text { startles. }\end{array}$ \\
\hline $\begin{array}{l}\text { Vehicle activity (from } \\
17 \mathrm{~m} \text { to hundreds of } \\
\mathrm{m} \text { ) }\end{array}$ & 18 & 7.37 & & 16 & $\begin{array}{l}\text { Hypervigilant if a vehicle } \\
\text { approached and always kept } \\
\text { her distance when a vehicle } \\
\text { was moving. Usually ran if a } \\
\text { vehicle passed the enclosure } \\
\text { (e.g., keeper truck). }\end{array}$ \\
\hline Eating & 6 & & 1.71 & 5 & $\begin{array}{l}\text { Stood while eating and scanned } \\
\text { area occasionally, often } \\
\text { included looking upward. } \\
\text { Occasionally ate with tail } \\
\text { between her legs. }\end{array}$ \\
\hline $\begin{array}{l}\text { Neighboring rancher's } \\
\text { gunshots }\end{array}$ & 2 & 0.60 & 3.33 & 2 & $\begin{array}{l}\text { Scanned her surroundings. Often } \\
\text { at rest when gunshots occurred } \\
\text { but usually did not get up. }\end{array}$ \\
\hline Observer's activities & 2 & 7.33 & 0.27 & 2 & $\begin{array}{l}\text { Occurred once when the observer } \\
\text { stepped on a stick and when } \\
\text { the observer sat down to begin } \\
\text { observations. }\end{array}$ \\
\hline No apparent stressor & 9 & 13.75 & 0.65 & 8 & $\begin{array}{l}\text { Occurred during usual rest and } \\
\text { activity periods. She appeared } \\
\text { to be calmly scanning her } \\
\text { surroundings and included } \\
\text { looking upward. }\end{array}$ \\
\hline
\end{tabular}

aTime given in hours. 'Percentage of Tenino's total number of look ups, which includes aircraft. 
tion, 1987). Tenino displayed these behaviors frequently and consistently. The other three animals displayed little if any of these behaviors. We suggest that Tenino has been repeatedly exposed to stressors involving uncontrollability and unpredictability, necessary factors in the etiology of PTSD (Foa et al., 1992), and that the stressors have come from two main sources: capture and captivity.

\section{Capture and Captivity}

During her darting by helicopter, Tenino may have been placed in an uncontrollable and unpredictable situation. During her capture, Tenino was "herded" from a forested area out into the open where she was shot and tranquilized (J. Fontaine, personal communication, November 1992). This situation could be considered uncontrollable because there was nothing she could have done to stop it and unpredictable because she now faced a novel situation in which there was little time to learn and implement evasive strategies. She also was reported to have entered a catatonic state (J. Fontaine, personal communication, November 1992) during her first capture, indicating that this procedure was emotionally traumatic.

The capture procedure was repeated a second time following the study animal's livestock depredation. The trauma of this event could be considered a repeated exposure to uncontrollable and unpredictable stress. Although aircraft was not involved, Tenino was shot and tranquilized an additional two times during her first month in captivity as twice she attempted to escape.

\section{Prop Planes Preferred}

Although Tenino did not look up at all aircraft that passed overhead, she looked up at enough to demonstrate an apparent preference for prop planes over jet aircraft. This matches well with her known background, in which she was captured using a helicopter. We hypothesize that Tenino might have looked up more at prop planes than jets because prop planes sound more like helicopters. When aircraft was present, Tenino occasionally flattened her ears as she looked up and, on rare occasions, would "duck" her head slightly as if something was about to fall on her. None of the other three wolves exhibited these behaviors whether aircraft were present or not.

\section{Behavioral Controls-With Limitations}

We were aware that using Gyrene and Gris Gris as behavioral controls had inherent limitations. Joe and Tenino were considered a mated pair, and the first author twice observed them mating during the several years of our study. Gyrene and Gris Gris, however, were siblings and probably were not a mated pair. Not having a potential 
"family" to protect — that is, pups—could have affected how they responded to perceived threats from the surrounding environment.

It also can be argued that because of their apparent visual impairments, Gyrene and Gris Gris did not look up at aircraft. Joe, however, did not look up either, and his vision apparently was intact. In addition, the immediate response to aircraft probably is auditory instead of visual, so both Gyrene and Gris Gris still could have reacted to aircraft in some obvious way - at least orienting their heads and ears to the sound. This was not observed. More important, the majority of Tenino's looks up were stress related, apparently involving events she perceived as threatening. If the other three wolves found these conditions stressful, they did not show it by looking up. On the contrary, Gyrene, Gris Gris, and often Joe, presumably in anticipation of food, would approach the fence nearest the arriving keeper truck. Tenino would remain at maximum distance. Her perception of a potential threat appeared to be different from that of the other wolves. Despite these limitations, Gyrene and Gris Gris were the only comparison group available at the time, and we felt that they were better than no group at all. All three comparison animals were useful in helping to determine the difference in the perceptions made by wolves raised in captivity versus Tenino, who grew up in the wild.

The individual's perception of a potential threat is important in determining the response (Foa et al., 1992). Tenino was not only a "wild" wolf, but also one who experienced trauma, having been captured twice for placement into captivity. Consequently, the data are indicating that she perceived potential threats in an environment where captive-reared wolves did not. In Table 2, her highest look up rate occurred when humans approached the enclosure.

Although Tenino's exposure to people had been limited, she had several years to adjust to their presence. Except for the first author, she apparently found the presence of others stressful, at least at the time of this study. It is expected that she would have found some keeper activities threatening, but the observer performed similar activities while traveling to and from her enclosure with the opposite results. This indicates that perhaps, under controlled conditions, Tenino might find some people less threatening if they approach her using a procedure similar to that of the observer.

\section{Importance of Predictability}

Our procedure involved being as predictable as possible. The observer always entered the area from the same place and always sat in the same locations. In addition, our study involved only one observer, the first author. The keepers entered the area from multiple directions and conducted maintenance tasks on Joe and Tenino's enclosure or at nearby enclosures. Occasionally, they entered the wolves' enclosure and often inspected the outside of the enclosure by walking all the way around it. 
At the time of our study, Wolf Haven had several keepers, all coming from different directions and conducting different tasks. Occasionally, they brought over a member of the board of trustees who wanted to view the wolves who were not on tour-like Joe and Tenino.

Over time, Tenino apparently perceived the observer's activities as less threatening than that of the keepers. This might have occurred because of a routine of predictability with the observer and the wolves, established at the beginning and maintained throughout most of the study. As the study was concluding near the end of 1994, the observer became increasingly involved in husbandry tasks involving Joe and Tenino-feeding and watering.

At this time, data collection on PTSD had concluded, and we were attempting to apply what we had learned to help improve Tenino's ability to deal effectively with human presence. Thus, the observer even entered their enclosure several times to feed both Joe and Tenino and to remove old pieces of uneaten meat. When a keeper entered the enclosure, Tenino would keep as far away as possible (the fence farthest away from the keeper) and would maintain a 180-degree position from the keeper as the keeper moved about the enclosure. When the observer entered the enclosure, Tenino- as well as Joe-would approach, but Tenino always maintained space between herself and the observer of approximately 8 to $15 \mathrm{~m}$. Although she demonstrated caution, she did not show signs of fear as she did with the keepers entering the enclosure, such as running in the opposite direction, flattening her ears, crouching, or looking up.

Also near the end of 1994, video from the remote camera was demonstrating that the observer's presence might have had a calming influence on Tenino. If Tenino was showing signs of anxiety before the observer's arrival such as hypervigilence or pacing back and forth, she would become calmer and often would sit down 15 to 20 min after the observer arrived.

The video also showed that if Tenino was calm in the observer's presence, she often would become anxious when the observer left the area. She would look intently in the direction where the observer walked off for up to $20 \mathrm{~min}$ before continuing her usual routine. Although this kind of information is a bit anecdotal, it was recorded when the observer was not present and helps to demonstrate that Tenino changed over time to become somewhat accepting of at least one person's presence. Even so, at the conclusion of this study in January 1995, human activity still appeared to be the primary stressor for Tenino.

\section{Stress and Socialization}

Tenino's looking up behaviors also might indicate that she was continually exposed to unknown amounts of stress. Regardless of human approaches, Table 2 indicates that human activities, both nearby and distant, might have helped to maintain her PTSD symptoms. This was supported by her own overall behavior in which she con- 
tinued to look up. She retained PTSD symptoms even after 3 years of captivity. In addition, once individuals perceive their environment as threatening, the mindset serves to sensitize them to future disturbing effects of uncontrollable and unpredictable stress (Chemtob, Roitblat, Hamada, Carlson, \& Twentyman, 1988). Although Table 2 is only a gross indicator of some possible contexts that Tenino might have perceived as threatening, it does demonstrate that some stressors did exist and appear to have perpetuated Tenino's symptoms of PTSD.

To some extent, some of Tenino's wariness and hypervigilance might have been a natural consequence of having lived in the wild. Klinghammer (1991) demonstrated that a social, sensitive period exists in wolves up to the first 21 days of life. Wolves who interact with humans during this time can become socialized to people. Without this experience, wolves maintain their natural fear of humans. Adult wild wolves placed into captivity, therefore, remain aloof and distant despite most rigorous attempts to socialize them (E. Klinghammer, personal communication, May 1995). Woolpy and Ginsburg (1967) succeeded in socializing wild wolves, and theirs is the only known method. Their method, however, was extremely stressful to the animals, and we felt that Tenino's past trauma and continuing stress would preclude attempting this process with her. Such elevated stress for prolonged periods ultimately could have proved detrimental rather than beneficial. In addition, her housing situation lacked the facilities to attempt socializing her in this manner.

\section{Death of the Wolves}

On May 1, 2001, Tenino died from sinus cancer (Engel, 2001) at the age of almost 11 years. The three other wolves also have died since the completion of the study: Joe in 1997 (10 years of age), and both Gyrene and Gris Gris in 2000 (16 years of age). Having worked at Wolf Haven International for several years, we found that by far the majority of wolves lived beyond 10 or 11 years of age, often up to 16 and 17 years.

Data obtained from Wolf Haven's Web page (Spring 2002) indicated that 39 wolves had died in this facility since it first opened in 1982. Of these 39 animals, 27 had known longevities ranging from 5 to 19 years of age. The 5-year-old was the exception, with every other wolf living 10 years or longer. There was a natural break in the data at 14 years, an age at which no wolves died. Of 27 wolves, 10 (37\%) died before the age of 14 years; 17 (63\%) lived beyond this point-10 of whom lived to be 16 or 17 years old. A similar pattern was found with the wolves at Wolf Park in Battle Ground, Indiana (E. Klinghammer, personal communication, May 1995).

We believe that at the time of the study, continuing stressors perpetuated Tenino's PTSD symptoms and made it difficult, if not impossible, for her to con- 
struct a functional Umwelt of her captive surroundings. Trauma does not lend itself easily to habituation, especially if the stressors persist (E. Klinghammer, personal communication, May 1995). In this case, the stressors were known to be human presence, human activity, and aircraft. Any number of reasons-genetics, stress, trauma, housing, or simply chance - could have contributed to Tenino's early demise, at least compared with the longevity of other captive wolves. On the other hand, we also are not surprised that she died at the lower end of the longevity spectrum for captive wolves.

\section{Stressors and Responses}

For Tenino to have become comfortable with her surroundings, we recommended to Wolf Haven at the time of this study that the stressors be removed before additional people and activity were introduced. Consequently, Wolf Haven responded twice by changing circumstances that we found to have negative affects on Tenino's behavior and those of the other wolves in the immediate area. Once Wolf Haven understood that Tenino was afraid of vehicle activity, the food truck was no longer driven up to the enclosure fence to feed Joe and Tenino. In addition, the observer found that the public had access to the back of Wolf Haven's property where Joe and Tenino's enclosure was located.

People, with their children and even their pet dogs, would sit next to the compound fence and watch Joe and Tenino, whose enclosure was only about $10 \mathrm{~m}$ away. While Tenino looked for a place to hide and keep her distance, Joe became aggressive (raised tail, raised hackles, approached the people and their pets) and followed the dogs' activities as best he could from the enclosure. At times, these people walked down the access road virtually next to Gyrene and Gris Gris's enclosure (Figure 1), both of whom responded to the dogs in a similar manner as that of Joe. In response to this, Wolf Haven built a secondary fence made of wire mesh on the outside of the compound in this area.

\section{Morals and Ethics}

It seems apparent that housing wild wolves in captivity is problematic and quickly can raise moral and ethical issues. Supplying Tenino with a quality life was extremely difficult at the time of our study, given the limited resources available to Wolf Haven and the numerous agendas involved in her care. As we attempted to understand the Umwelt of Tenino and the other three study animals, it became apparent to us that the Umwelt of Wolf Haven and those of the people in charge were critical factors in supplying a unique quality of care for Tenino that our data suggested she needed. 
Wolf Haven's priority always had been on housing wolves raised in captivity. At the time, Tenino was the only resident from the wild. In addition, she came from the natural recovery area, one of three areas involved in wolf recovery in the northwest United States. The other two areas involved reintroducing wolves into Yellowstone National Park and central Idaho. Although wolf recovery is currently still in progress, reintroduction was a controversial subject at the time of our study. The people involved at Wolf Haven, from volunteers to employees and board members, were not exempt from airing their views on this subject. They based their views very much on their morals and ethics as to what they would have liked wolf recovery to accomplish; bringing a wolf from the wild into captivity sparked much debate at Wolf Haven.

\section{Perpetuation of Stressors}

Despite everyone's views, our data began demonstrating that not only did Tenino fit the profile of a PTSD victim, but that Wolf Haven had placed her in a situation where several of the stressors involved in her development of PTSD - aircraft and gunshots-were still present and out of Wolf Haven's control. In addition, our data demonstrated that Wolf Haven occasionally contributed to the perpetuation of these stressors.

Table 2 indicates that the majority of stress-related looks up occurred because of human presence (both distant and close), vehicle activity from Wolf Haven's parking lot and up close with the keeper truck, and construction that Wolf Haven was undergoing at the time. From a business standpoint, it would not have been practical to change any of these factors to accommodate only one wolf; obviously, they were not changed. Nevertheless, they were within Wolf Haven's control to change. Until our study, however, no one knew that Wolf Haven's daily activities tended to disrupt Tenino's behavior and helped to perpetuate her symptoms of PTSD.

Not only were stressors present, but Table 1 demonstrates that, at least occasionally, Tenino experienced multiple stressors either simultaneously or in close succession. During one observation session, a wood chipper was operating nearby for maintenance reasons, which—given her pacing and flat ears-Tenino apparently found uncomfortable. The other three study animals were all sitting. She finally sat down, and the wood chipper backfired, causing an exaggerated startle in Tenino. The other wolves remained seated. She began walking, again with flat ears, only to stop and stand motionless moments later as a prop plane flew over the enclosure. With her ears remaining flat, she looked up at the plane as it flew by. When the wood chipper was turned off a few minutes later, she finally sat down again.

Over the next $2 \mathrm{hr}$, the wood chipper occasionally was on and off. During this time, two photographers approached the enclosure to take pictures of Joe and Tenino. Tenino repeatedly trotted from where she was sitting to a vantage point, monitored the photographers' location, and then returned to sitting. While she was 
attending to the photographers, the wood chipper produced multiple backfires and Tenino jumped and produced another exaggerated startle. She then trotted to the other side of the enclosure closest to the chipper and stood looking in that direction. Joe was either sitting or lying down through most of these events and Gyrene and Gris Gris were out of view. This wolf clearly was trying to monitor multiple threats, not only from several directions on the ground but also from above.

\section{CONCLUSIONS}

We feel that our findings raised moral and ethical issues regarding animal welfare and husbandry, which made Wolf Haven feel uncomfortable. For the duration of our study, the board of trustees at Wolf Haven struggled to decide what should be the best course of action regarding Tenino's welfare, given the data we had collected. Everyone had an opinion and often felt quite strongly about it. The opinions ranged from euthanizing Tenino to abolishing our study.

We also found that misinterpretations of Tenino's behaviors by the Wolf Haven staff tended to aggravate Tenino's emotional disorder. In one instance, the head keeper reported that Tenino was calm when he walked up to her enclosure that day, but the video from the remote camera showed her running away from him as he approached. When the keeper arrived near the enclosure, where trees no longer obstructed his view, Tenino stopped running and stood looking from a distance as the keeper walked by the fence line. He naturally reported then that Tenino was calm. We are concerned that quality care for a captive animal be based on reliable information via observations and study rather than on personal biases and incomplete information, especially for a wild animal placed into captivity.

The point here is that all the arguing and the mix of everyone's morals and ethics delayed, at the time, what little could have been done for Tenino. Consequently, her surroundings, as well as the existence of the stressors that perpetuated her PTSD, remained virtually the same. We feel that the lack of action and ignorance- - even with good intentions-is detrimental to the very animals about whom one claims to care. For Tenino, her behavior indicated that, under less stressful conditions, she could have been tamed and her fear of humans reduced. In the future, however, we hope that problems with wolves in the wild can be resolved in the field rather than by violating their Umwelt and forcing them to create a new one in captivity.

\section{ACKNOWLEDGMENT}

We thank Joe Fontaine and Steve Fritts, U.S. Fish and Wildlife Service and Erich Klinghammer, director of Wolf Park, Battle Ground, IN, for the information they provided through personal communications. 


\section{REFERENCES}

American Psychiatric Association. (1987). Diagnostic and statistical manual of mental disorders (3rd ed., rev.). Washington, DC: Author.

Chemtob, C., Roitblat, H., Hamada, R., Carlson, J., \& Twentyman, C. (1988). A cognitive action theory of post-traumatic stress disorder. Journal of Anxiety Disorders, 2, 253-275.

Engel, J. (2001). From out of the wild and into our hearts-Tenino Montana. Wolf Tracks, 18, 5-6.

Foa, E. B., Zinbarg, R., \& Rothbaum, B. O. (1992). Uncontrollability and unpredictability in post-traumatic stress disorder: An animal model. Psychological Bulletin, 112(2), 218-238.

Foy, D. W., Resnick, H. S., Sipprelle, R. C., \& Carroll, E. M. (1987). Premilitary, military, and post-military factors in the development of combat-related posttraumatic stress disorder. Behavior Therapist, 10, 3-9.

Hediger, H. (1950). Wild animals in captivity: An outline of the biology of zoological gardens. New York: Dover.

Helzer, J. E., Robins, L. N., \& McEvoy, L. (1987). Posttraumatic stress disorder in the general population. New England Journal of Medicine, 317, 630-634.

Kilpatrick, D. G., Saunders, B. E., Amick-McMullan, A., Best, C. L., Veronen, L. J., \& Resnick, H. S. (1989). Victim and crime factors associated with the development of crime-related post-traumatic stress disorder. Behavior Therapy, 29, 177-198.

Klinghammer, E. (1991). Imprinting and early experience: How to avoid problems with tame animals. In D. Ludwig (Ed.), Wildlife rehabilitation (pp. 135-142). Schaumburg, IL: 9th Annual Symposium of the National Wildlife Rehabilitators Association.

Kolb, L. C. (1987). A neuropsychological hypothesis explaining post-traumatic stress disorders. American Journal of Psychiatry, 144, 989-995.

Maier, S. F., \& Keith, J. R. (1987). Shock signals and the development of stress-induced analgesia. Journal of Experimental Psychology: Animal Behavior Processes, 13, 226-238.

Mallonée, J. S. (1991). Behaviour of gray whales (Eschrichtius robustus) summering off the northern California coast, from Patrick's Point to Crescent City. Canadian Journal of Zoology, 69, 681-690.

Masserman, J. H. (1971). The principle of uncertainty in neurotigenesis. In H. Dimmel (Ed.), Experimental psychopathology: Recent research and theory (pp. 13-32) San Diego, CA: Academic.

Mineka, S. (1985). Animal models of anxiety based disorders. In A. H. Tuma \& J. D. Maser (Eds.), Anxiety and anxiety disorders (pp. 199-244). Hillsdale, NJ: Lawrence Erlbaum Associates, Inc.

Mineka, S., \& Kihlstrom, J. F. (1978). Unpredictable and uncontrollable events: A new perspective on experimental neurosis. Journal of Abnormal Psychology, 2, 256-271.

Moye, T. B., Hyson, R. L., Grau, J. W., \& Maier, S. F. (1983). Immunization of opiod analgesia: Effects of prior escapable shock on subsequent shock-induced and morphine-induced antinociception. Learning and Motivation, 14, 238-251.

Rachman, S. (1989). Fear and courage (2nd ed.). New York: Freeman.

Saigh, P. A. (1988). Anxiety, depression, and assertion across alternating intervals of stress. Journal of Abnormal Psychology, 97, 338-341.

Speed, N., Engdahl, B., Schwartz, J., \& Eberly, R. (1989). Posttraumatic stress disorder as a consequence of POW experience. Journal of Nervous and Mental Disease, 177, 1447-1453.

van der Kolk, B. A. (1987). Psychological trauma. Washington, DC: American Psychiatric Press.

van der Kolk, B. A., Greenberg, M. S., Boyd, H., \& Krystal, J. (1985). Inescapable shock, neurotransmitters, and addition to trauma: Towards a psychology of post-traumatic stress. Biological Psychiatry, 20, 314-325.

von Uexküll, J. (1937). Das Problem des Heimfindens bei Menschen und Tieren. Der primare und sekundare Raum [The problem of searching for homes by man and animal. The primary and secondary habitat]. Z. ges. Naturwiss, 2, 457-467.

Woolpy, J. H., \& Ginsburg, G. E. (1967). Wolf socialization: A study of temperament in a wild social species. American Zoology, 7, 357-363. 